\title{
MELHORAMENTO PARA RESISTÊNCIA PARCIAL A MOLÉSTIAS FÚNGICAS EM CEREAIS
}

\author{
BREEDING FOR PARTIAL RESISTANCE TO FUNGAL DISEASES IN CEREALS
}

\author{
Gladis Cleci Hermes Thomé ${ }^{1}$ Sandra Cristina Kothe Milach ${ }^{2}$ \\ Renata Pereira da Cruz ${ }^{3}$ Luiz Carlos Federizzi ${ }^{4}$
}

\author{
- REVISÃO BIBLIOGRÁFICA -
}

RESUMO

A resistência parcial é uma estratégia promissora para ser utilizada pelos melhoristas de plantas na tentativa de aumentar a eficiência no lançamento de cultivares com resistência durável. O objetivo deste artigo é o de discutir os principais aspectos da utilização prática desse tipo de resistência em programas de melhoramento de cereais. As formas de avaliação da resistência parcial, as dificuldades de selecionar esta característica e a durabilidade deste tipo de resistência são discutidas. Alternativas para utilização da resistência parcial em programas de melhoramento são apresentadas e representam, hoje, uma estratégia importante no desenvolvimento de genótipos com maior estabilidade de desempenho frente aos ambientes variáveis e propícios à ocorrência de moléstias fúngicas em cereais.

Palavras-chave: componentes da resistência, resistência durável, progresso lento da moléstia, melhoramento genético vegetal.

\section{SUMMARY}

Partial resistance is a promising strategy to be used by plant breeders in an attempt to increase the efficiency in producing cultivars with durable resistance. The objective of this paper is to discuss the utilization of this type of resistance in cereal breeding programs. Aspects as mode of evaluation, difficulties in selecting for and the durability of partial resistance are discussed. Alternatives to use partial resistance in breeding programs are presented and they represent an important strategy to develop genotypes with more stable performance in environments suitable for fungus disease development.

Key words: resistance components, durable resistance, slow rusting, plant breeding.

\section{INTRODUÇÃO}

As moléstias causadas por fungos são um dos principais fatores responsáveis por reduções significativas no rendimento de cereais. Em muitos casos, a proteção das culturas contra essas moléstias é necessária não somente para manter a capacidade de produção, mas também para prevenir efeitos negativos sobre a qualidade do produto (MARTINELLI $\boldsymbol{e t}$ al., 1994). Dentre as várias estratégias de controle, a resistência da planta destacase como o meio de proteção mais eficiente, não requerendo investimentos em produtos, maquinaria e mão-de-obra especializada.

Tradicionalmente, os programas de melhoramento têm explorado genes maiores, que conferem à planta resistência total, mas pouco durável. Segundo VAN GINKEL \& RAJARAM (1993), a popularidade do uso desse tipo de resistência se deve à alta herdabilidade, à mentalidade do agricultor que prefere ver sua lavoura totalmente livre de moléstias, e à pressão de mercado que, devido à competitividade, exige o lançamento freqüente de novos cultivares deixando a durabilidade da resistência em segundo plano.

A obtenção de resistência durável a patógenos em cereais, como os causadores das ferrugens, é dificultada pelo elevado número de raças virulentas dos mesmos. Este problema se agrava especial-

\footnotetext{
${ }^{1}$ Biólogo, Mestre, Aluna de Doutorado, Curso de Pós-graduação em Fitotecnia, Universidade Federal do Rio grande do Sul (UFRGS). Bolsista CAPES.

${ }^{2}$ Engenheiro Agrônomo, Professor Adjunto, PhD., Departamento de Plantas de Lavoura, Faculdade de Agronomia, UFRGS, CP. 776, 95501-970, Porto Alegre, RS. Autor para correspondência.

${ }^{3}$ Engenheiro Agrônomo, Mestre, Aluna de Doutorado, Curso de Pós-graduação em Fitotecnia, UFRGS. Bolsista CNPq.

${ }^{4}$ Engenheiro Agrônomo, Professor Titular, PhD., Departamento de Plantas de Lavoura, Faculdade de Agronomia - UFRGS.
} 
mente em espécies autógamas, geralmente cultivadas em vastas áreas como cultivares geneticamente uniformes, o que proporciona o surgimento e multiplicação de novas raças virulentas do patógeno. Estas, devido à baixa freqüência inicial, podem permanecer não detectadas durante o desenvolvimento da cultivar. $\mathrm{O}$ tempo necessário para que essas raças aumentem de frequiência na população e se adaptem a cultivares individuais é variável. Em alguns casos, pode ocorrer antes que o cultivar tenha sido explorado comercialmente de forma satisfatória causando sérios danos econômicos (JOHNSON, 1978).

A durabilidade da resistência é o ponto crucial para a eficiência do melhoramento e é amplamente influenciada por fatores genéticos, evolutivos e ambientais (JOHNSON, 1981). Muitas estratégias têm sido consideradas visando conferir proteção durável, onde o objetivo não é suprimir a população de patógenos inteiramente, mas evitar que atinja níveis prejudiciais à cultura hospedeira. Entre estas estratégias está a resistência parcial, que nas duas últimas décadas vem sendo sugerida como uma solução para o problema das moléstias.

Esta revisão tem como objetivos apresentar e discutir algumas questões pertinentes à utilização da resistência parcial no controle de moléstias fúngicas em cereais e a viabilidade de seleção para este tipo de resistência nos programas de melhoramento.

\section{O que é resistência parcial?}

A resistência parcial em cereais é conhecida há muito tempo, mas seu valor não foi totalmente apreciado até que grandes epidemias de ferrugem da folha devastaram as áreas de cultivo de trigo na década de 50 (WILCOXSON, 1981).

Segundo PARLEVLIET \& ZADOKS (1977), a resistência parcial é quantitativa, baseada em genes de pequeno efeito no fenótipo. Tem sido relatada para cereais como aveia, arroz, cevada e trigo (LUKE et al., 1972; JOHNSON \& WILCOXSON, 1978; KUHN et al., 1978; MALAVOLTA et al., 1995; PEARCE \& VAN SANFORD, 1996). Porém, a expressão da resistência parcial é complexa e de difícil avaliação; em alguns casos é controlada por genes maiores, dominantes ou recessivos, sendo em outros, controlada por grande número de genes de pequeno efeito que atuam sobre diferentes componentes da resistência.

O progresso lento da moléstia é o principal efeito da resistência parcial sobre os diversos componentes, tais como: baixa freqüência de infecção, longo período de latência, lesões de tamanho pequeno, baixa intensidade de esporulação e curto período infeccioso (VAN DER PLANK, 1963). O efeito de cada componente é pequeno, mas o efeito combinado pode representar redução na taxa de progressão da moléstia (PARLEVLIET \& VAN OMMEREN, 1975; PARLEVLIET, 1979).

A resistência parcial é um caráter quantitativo, situando-se em algum ponto entre a completa resistência e a completa suscetibilidade. Por isso, o melhoramento para resistência parcial enfrenta os mesmos desafios de qualquer outro caráter com este tipo de herança genética, mas com uma dificuldade a mais. Ao contrário de outros caracteres quantitativos, não só a planta e o ambiente, mas também o patógeno influenciam a variabilidade fenotípica final.

\section{Avaliação da resistência parcial}

Para avaliar a resistência de uma cultivar à determinada moléstia, pode-se medir a quantidade de patógeno nele presente num dado momento, comparada à quantidade presente num cultivar controle extremamente suscetível. Porém, medir a quantidade de patógeno é normalmente impossível, já que este nem sempre é facilmente visualizado. Entretanto, podem ser avaliados os efeitos do patógeno sobre o hospedeiro, ou seja, as lesões causadas pelo patógeno (PARLEVLIET, 1993).

Numerosos estudos têm demonstrado que medir a quantidade de tecido afetado pelo patógeno proporciona uma estimativa acurada da severidade de infecção (NEERVOORT \& PARLEVLIET, 1978; JOHNSON \& WILCOXSON, 1979). Entretanto, esta não depende só do nível de resistência do cultivar; por isso, precisam ser avaliados vários componentes relacionados também à capacidade de colonização e adaptação do patógeno como o período de latência, tamanho e número de lesões, produção de esporos, a severidade de infecção e o progresso da moléstia.

O período de latência refere-se ao período de tempo decorrido desde a inoculação das plantas (contato entre patógeno e hospedeiro) até que as primeiras lesões rompam a epiderme expondo as estruturas reprodutivas do patógeno. Um período de latência maior é consequiência da maior resistência da planta à infecção e colonização pelo patógeno. Conseqüentemente, menor número de ciclos do patógeno serão produzidos sobre esta planta e menor será a severidade da moléstia no final do ciclo da cultura. Este componente tem sido amplamente utilizado devido à relativa facilidade e rapidez de determinação (PARLEVLIET $\boldsymbol{e t}$ al., 1980; JACOBS \& BROERS, 1989; ROUMEN, 1996).

O tamanho e número de lesões e a esporulação refletem a resistência da planta à colonização e multiplicação do patógeno. Assume-se que o 
tamanho de lesão reflete a taxa de crescimento do patógeno e, conseqüentemente, a produção de esporos (PARLEVLIET, 1979). O tamanho das lesões geralmente é determinado a partir das medidas de comprimento e largura realizadas com o auxílio de lupa ou microscópio (THOMÉ et al., 1997b), as quais podem ser usadas para calcular a área das lesões. As lesões podem ser contadas também com o auxílio de lupa, numa área da folha ou tecido da planta. A determinação do número de esporos produzidos pode ser feita por lesão ou por área de tecido, através da pesagem dos esporos ou contagem dos mesmos com o auxílio de equipamentos específicos (NEERVOORT \& PARLEVLIET, 1978).

A severidade da moléstia é avaliada em termos de área do tecido hospedeiro ocupada pelas lesões causadas pelo patógeno e reflete o nível de resistência do hospedeiro devido às variações nos componentes acima citados. As avaliações podem ser feitas em nível de parcela, planta individual ou folhas isoladas (geralmente a folha bandeira). Atualmente, essas avaliações são feitas com o auxílio de escalas, como a elaborada por PETERSON et al. (1948), que são diagramas onde estão representadas diferentes densidades de lesões e que auxiliam na estimativa visual da percentagem de severidade. Essa é uma avaliação subjetiva que pode variar com diferentes avaliadores.

A área sob a curva do progresso da doença (ASCPD) é útil para revelar pequenas diferenças de severidade e níveis de resistência. Muitos pesquisadores têm utilizado a ASCPD para identificar e caracterizar genótipos hospedeiros que apresentem progresso lento de diversas moléstias fúngicas (SINGLETON $\boldsymbol{e}$ t al., 1982; SINGH \& RAO, 1989; DAS et al., 1992; MILACH et al., 1996). São feitas avaliações seqüenciais de severidade em intervalos regulares de tempo, os dados de severidade são plotados num gráfico em função do tempo e calcula-se a ASCPD. Em genótipos suscetíveis, a moléstia geralmente começa antes e desenvolve-se rapidamente, resultando numa maior ASCPD quando comparados com um genótipo com resistência parcial onde a moléstia começa mais tarde e/ou desenvolve-se mais lentamente.

Períodos de latência mais prolongados, lesões menores e menor produção de esporos são componentes que atrasam ou reduzem a magnitude de vários estágios do ciclo reprodutivo do patógeno, tornando mais lento o progresso da moléstia a campo (SHANER \& HESS, 1978). Vários estudos mostraram a alta correlação destes componentes com a resistência parcial a moléstias fúngicas em cereais (OHM \& SHANER, 1976; ANDRES \& WILCOXSON, 1986). Porém, levando em conside- ração o modo como estes componentes precisam ser avaliados surge a seguinte dúvida: será viável selecionar para resistência parcial nos programas de melhoramento? Para chegar a uma resposta para esta pergunta é preciso analisar alguns aspectos pertinentes ao processo de seleção para resistência parcial nos programas de melhoramento de cereais.

\section{Melhoramento para resistência parcial}

A transferência da resistência parcial para novos cultivares através do melhoramento clássico, requer a identificação deste tipo de resistência nos genótipos parentais e nas populações segregantes durante o processo de seleção. Esta pode ser uma tarefa difícil, principalmente porque é influenciada por inúmeros fatores.

Melhoristas que trabalham com resistência total, condicionada por genes de grande efeito no fenótipo fazem, em geral, avaliações no campo para detectar apenas se as plantas apresentam ou não a moléstia. Em alguns casos, inclusive, é feita somente uma avaliação da moléstia durante todo o ciclo da cultura, geralmente na época do florescimento. $\mathrm{Na}$ prática, uma única avaliação não é suficiente para detectar resistência parcial, principalmente, no caso de moléstias policíclicas como as ferrugens, que tipicamente começam com níveis muito baixos de infecção (SHANER, 1996). Em trabalhos com resistência parcial no campo, geralmente precisam ser feitas várias avaliações da moléstia para contornar estes problemas, usando a ASCPD. Para ser o mais precisa possível, a ASCPD da ferrugem em cereais, por exemplo, requer que sejam feitas avaliações seqüenciais com intervalos não superiores a uma semana e um mínimo de três avaliações. Isto é quase impraticável em grandes programas de melhoramento onde há inúmeras plantas por população segregante e dezenas de gerações para serem avaliadas.

A avaliação do número e tamanho das lesões é muito trabalhosa e a dificuldade de realizar estas medidas sugere que este não é um processo prático, a menos que muitas pessoas possam ser envolvidas nestas tarefas. Se centenas de linhagens precisam ser avaliadas num dia, como é o caso típico em programas de melhoramento, aparentemente ainda não há substituto prático para a avaliação visual.

Grande parte das pesquisas mostra que um maior número de genes está envolvido no controle da resistência parcial que no controle da resistência total (PARLEVLIET, 1976, WILCOXSON, 1981). Isso não estabelece que a resistência parcial seja sempre conferida por grande número de genes de pequeno efeito, mas deve ser levado em conside- 
ração pelo melhorista para a escolha da estratégia adequada de seleção.

Além disso, a maioria dos cultivares modernos de cereais, bem como linhagens adaptadas, apresentam genes para resistência total (CRUZ, 1996). Este germoplasma é constantemente utilizado nos cruzamentos; portanto, genes para resistência total a raças específicas do patógeno podem estar segregando nas populações nas quais se quer selecionar a resistência parcial. A presença destes genes pode mascarar os genes de resistência parcial dificultando a seleção, como foi observado por PARLEVLIET \& VAN OMMEREN (1988), trabalhando com os patossistemas aveia - Puccinia coronata e cevada - P. hordei.

Há avaliações que somente podem ser feitas em ambiente controlado, como a determinação do período de latência e da produção de esporos em função do tempo; outras podem ser feitas no campo com a vantagem de se estimar também a interação com o ambiente. DAS et al. (1993) observaram que a correlação pode ser alta entre componentes avaliados nos dois tipos de ambiente.

A campo, a resistência geralmente é avaliada em parcelas relativamente pequenas e adjacentes num ambiente altamente propício ao desenvolvimento da moléstia, o que pode levar a erros de estimativa devido à interferência entre parcelas (KNUDSEN et $\boldsymbol{a l}$., 1986; BROERS \& LOPEZATILANO, 1995). Entretanto, estes problemas podem ser contornados com o uso de parcelas experimentais isoladas e de tamanho adequado (BROERS et al., 1996).

Mesmo tomando-se todos os cuidados possíveis no que se refere à seleção para resistência parcial, não há garantias de que a mesma será durável. Segundo JOHNSON (1984), resistência durável é aquela que permanece efetiva durante o cultivo prolongado do cultivar resistente em vastas áreas $\mathrm{e}$ em ambientes favoráveis para o desenvolvimento da moléstia. Nenhum método experimental se assemelha a este teste definitivo, embora duas alternativas sejam geralmente propostas: testar em vários locais, o que é um passo indispensável do melhoramento para testar a adaptação de novos cultivares, e testar com diversas raças do patógeno.

Apesar de não haver garantia de durabilidade para a resistência parcial, JOHNSON (1978) e WILCOXSON (1981) relataram vários exemplos em que este tipo de resistência tem se mantido efetivo após dezenas de anos de observações em diversos patossistemas e nas mais diferentes regiões do mundo como a África, Europa e América do Norte, tanto em nível experimental quanto em condições de cultivo extensivo.

\section{Uso da resistência parcial em programas de me- lhoramento}

A meta principal desta revisão foi avaliar o assunto de forma crítica, apresentando alguns dos problemas envolvidos. E, como pôde ser observado, a seleção para resistência parcial não é uma tarefa fácil.

Bons métodos de seleção, que consigam diferenciar pequenas variações nos níveis de resistência, são absolutamente essenciais para se identificar níveis satisfatórios de resistência. Nesse sentido, torna-se essencial investir no desenvolvimento e utilização de novas técnicas que facilitem o trabalho de seleção. Os avanços da informática, nos últimos anos, têm viabilizado operações como a análise de imagens digitalizadas, que já vem sendo utilizada para quantificar área foliar infectada por moléstias (KAMPMANN \& HANSEN, 1994; THOMÉ $\boldsymbol{e t}$ al., 1997a).

O melhoramento para caracteres quantitativos como a resistência parcial a moléstias torna-se difícil, principalmente porque os efeitos de genes individuais controlando estes caracteres não podem ser facilmente identificados. Neste sentido, as modernas técnicas da biologia molecular, especialmente o uso de marcadores moleculares para identificar e manipular segmentos de cromossomos controlando caracteres quantitativos - QTLs ("Quantitative Trait Loci"), podem aumentar a eficiência da seleção (DUDLEY, 1993).

Já foram mapeados QTLs para resistência parcial a várias moléstias como a brusone do arroz (YU et al., 1991), o oídio da cevada (HUEN, 1992) e a mancha foliar do milho (BUBECK $\boldsymbol{e t}$ al., 1993). Os QTLs serão úteis para determinar o número de locos envolvidos na resistência parcial e a ocorrência ou não de epistasia. Além disso, os QTLs podem ser úteis para alcançar uma meta ainda mais ambiciosa: clonar genes de resistência parcial até agora conhecidos apenas pelo seu efeito pequeno e contínuo sobre o fenótipo (YOUNG, 1996). Esta técnica possibilitará aos melhoristas selecionar com base no genótipo e não no fenótipo, que no caso da resistência parcial é de avaliação difícil, demorada e pouco precisa. Contudo, do mapeamento molecular de QTLs para resistência parcial em cereais, até a utilização desses para seleção assistida por marcadores moleculares (SAMM) em programas de melhoramento, existe um caminho a percorrer (MILACH, 1998a). Os marcadores moleculares empregados no mapeamento, como os de RFLP ("Restriction Fragment Length Polymorphism"), AFLP ("Amplified Fragment Length Polymorphism") e microsatélites, são ainda de difícil utilização rotineira para avaliação de um grande número de indivíduos. A conver- 
são destes em tipos de marcadores de mais fácil utilização, como STS ("Simple Tagged Sequence"), possibilitará a incorporação rotineira de SAMM no melhoramento para resistência parcial em cereais (MILACH, 1998b).

Cabe ressaltar que o melhoramento genético não pode continuar dependendo apenas da resistência conferida por genes maiores, pois a dinâmica das populações patogênicas sob tais condições de pressão seletiva é muito intensa, possibilitando o rápido surgimento de novas raças virulentas.

As pesquisas indicam que há variabilidade potencial no germoplasma atual para resistência parcial e/ou durável à maioria das moléstias fúngicas que atacam os cereais. Os melhoristas precisam estar cientes de que aumentar a durabilidade da resistência a determinada moléstia significa aumentar a vida útil de um cultivar, potencializando os recursos investidos no desenvolvimento do mesmo.

$\mathrm{Na}$ literatura, encontram-se várias propostas e relatos da viabilidade de seleção para resistência parcial às ferrugens do trigo (OHM \& SHANER, 1976; LINE \& CHEN, 1995), à ferrugem da folha e oídio da cevada (PARLEVLIET \& VAN OMMEREN, 1988) e à ferrugem da folha da aveia (SHANER, 1996).

Assumindo-se que, num programa de melhoramento, a seleção é feita essencialmente a campo, com exposição à mistura de raças do inóculo natural, pode-se proceder seleção para acumulação de genes menores. Em genótipos fixos, bem como em populações segregantes, pode-se selecionar contra suscetibilidade mais que para resistência, eliminando as plantas mais suscetíveis e as totalmente resistentes. Entre as restantes, pode-se proceder seleção e recombinação, processo denominado seleção recorrente contra suscetibilidade e contra genes maiores. Sem dúvida, esta mudança de filosofia deverá ser gradual, com a manutenção de diferentes pools gênicos para resistência total e resistência parcial, o que permitirá a exploração efetiva de ambos os tipos de resistência. Além disso, este processo permitirá o acúmulo de genes menores no germoplasma do programa até atingir níveis suficientes para o lançamento de novas variedades com resistência parcial.

\section{CONCLUSÕES}

A necessidade de obtenção de resistência mais durável às moléstias é uma realidade e a resistência parcial é uma provável solução. Apesar das dificuldades, as pesquisas com cereais têm mostrado que, utilizando métodos adequados, é possível acu- mular genes de resistência parcial a moléstias fúngicas em genótipos elite.

A utilização efetiva da resistência parcial na rotina dos programas de melhoramento requer uma mudança na filosofia de trabalho do melhorista, acostumado a explorar genes de grande efeito no fenótipo e, por isso, de fácil seleção. Neste sentido, o trabalho integrado com profissionais de diferentes áreas como a fitopatologia, a biologia molecular e até mesmo a informática, será indispensável para atingir resultados satisfatórios na seleção e acúmulo de genes para resistência parcial.

Na prática, o uso de cultivares com resistência parcial vai necessitar de um trabalho árduo por parte de melhoristas e extensionistas na conscientização dos agricultores que tradicionalmente preferem ter sua lavoura totalmente livre de moléstias. Essa conscientização precisa ser feita no sentido de mostrar que esta é, provavelmente, a melhor alternativa para obter durabilidade de resistência e aumentar as chances de se alcançar estabilidade de produção.

\section{REFERÊNCIAS BIBLIOGRÁFICAS}

ANDRES, M.W., WILCOXSON, R.D. Effect of pathogen races on the area under the disease progress curve in barley infected with Puccinia hordei. Journal of Plant Disease and Protection, Stuttgart, v. 93, n. 6, p. 632-637, 1986.

BROERS, L.H.M., LOPEZ-ATILANO, R.M. Effect of interplot interference on the assessment of partial resistance to stem rust in Durum wheat. Phytopathology, St. Paul, v. 85, n. 2, p. 233-237, 1995.

BROERS, L.H.M., CUESTA SUBÍAS, X., LÓPEZ-ATILANO, R.M. Field assessment of quantitative resistance to yellow rust in ten spring bread wheat cultivars. Euphytica, Wageningen, v. 90 , p. $9-16,1996$

BUBECK, D.M., GOODMAN, M.M., BEAVIS, W.D., $\boldsymbol{e} \boldsymbol{t}$ al. Quantitative trait loci controlling resistance to gray leaf spot in maize. Crop Science, Madison, v. 33, p. 838-847, 1993.

CRUZ, R.P. Genética da resistência à ferrugem da folha e os seus efeitos sobre caracteres da panícula de aveia. Porto Alegre - RS. 81 p. Tese (Mestrado em Fitotecnia) - Programa de Pós-graduação em Agronomia, Universidade Federal do Rio Grande do Sul, 1996.

DAS, M.K., RAJARAM, S., KRONSTAD, W.E., $\boldsymbol{e}$ t $\boldsymbol{a}$. Associations and genetics of three components of Slowrusting in leaf rust of wheat. Euphytica, Wageningen, v. 68, p. 99-109, 1993.

DUDLEY, J.W. Molecular markers in plant improvement manipulation of genes affecting quantitative traits. Crop Science, Madison, v. 33, p. 660-668. 1993.

HUEN, M. Mapping quantitative powdery mildew resistance of barley using a restriction fragment length polymorphism map. Genome, Ottawa, v. 35, p. 1019-1025, 1992. 
JACOBS, T.H., BROERS, L.H.M. The inheritance of host plant effect on latency period of wheat leaf rust in spring wheat. I: Estimation of gene action and number of effective factors in $\mathrm{F}_{1}, \mathrm{~F}_{2}$ and backcross generations. Euphytica, Wageningen, v. 44, p. 197-206, 1989.

JOHNSON, R. Practical breeding for durable resistance to rust diseases in self-pollinating cereals. Euphytica, Wageningen, v. 27 , p. $529-540,1978$

JOHNSON, R. Durable resistance: definition of, genetic control and attainment in plant breeding. Phytopathology, St. Paul, v. 71, n. 6 , p. $567-568,1981$.

JOHNSON, R. A critical analysis of durable resistance. Annual Review of Phytopathology, Palo Alto, v. 22, p. 309-330, 1984.

JOHNSON, R., WILCOXSON, R.D. Components of slow-rusting in barley infected with Puccinia hordei. Phytopathology, St Paul, v. 68, p. $1470-1474,1978$.

JOHNSON, R., WILCOXSON, R.D. Inheritance of slow rusting of barley infected with Puccinia hordei and selection of laten period and number of uredia. Phytopathology, St. Paul, v. 69 p. $145-151,1979$

KAMPMANN, H.H., HANSEN, O.B. Using color image analysis for quantitative assessment of powdery mildew on cucumber. Euphytica, Wageningen, v. 79, p. 19-27, 1994.

KNUDSEN, J.CHR.N,, DALSGAARD, H.H., JORGENSEN, J.H. Field assessment of partial resistance to powdery mildew in spring barley. Euphytica, Wageningen, v. 35, p. 233-243, 1986

KUHN, R.C., OHM, H.W., SHANER, G.E. Slow leaf-rusting resistance in wheat against twenty-two isolates of Puccinia recondita. Phytopathology, St. Paul, v. 68, p. 651-656, 1978.

LINE, R.F., CHEN, X. Successes in breeding for and managing durable resistance to wheat rusts. Plant Disease, St. Paul, v. 79 , n. 12 , p. $1254-1255,1995$

LUKE, H.H., CHAPMAN, W.H., BARNETT, R.D. Horizontal resistance of red rustproof oats to crown rust. Phytopathology, St. Paul, v. 62, p. 414-417, 1972.

MALAVOLTA, V.M.A., PETTINELLI Jr., A., FANTIN, G.M., et al. Determinação de níveis de resistência parcial à brusone em cinco genótipos de arroz. Summa Phytopathologica, Jaboticabal, v. 21, p. 117-123, 1995

MARTINELli, J.A., FEDERIZZI, L.C., BENNEDETTI, A.C. Redução do rendimento de grãos da aveia em função da severidade da ferrugem da folha. Summa Phytopathologica, Jaboticabal, v. 20, p. 116-118, 1994

MILACH, S.C.K., THOMÉ, G.C.H., FEDERIZZI, L.C., et al. Characterization of partial resistance to oat crown rust through the area under the disease progress curve. In: V INTERNATIONAL OAT CONFERENCE \& VII INTERNATIONAL BARLEY GENETICS SYMPOSIUM, 1996. Saskatoon, Canada. Proceedings... Saskatoon: University of Saskatchewan, 1996, v. 2, 814 p., p. 752-754.

MILACH, S.C.K. Marcadores de DNA: aplicações no melhoramento de plantas. Biotecnologia, Ciência e Desenvolvimento, Brasília, v. 1, n. 5, p. 14-17, 1998a.
MILACH, S.C.K. Mapeamento molecular de características de importância agronômica. In: S.C.K. MILACH. Marcadores moleculares em plantas. Porto Alegre, p. 67-73, 1998b.

NEERVOORT, W.J., PARLEVLIET, J.E. Partial resistance of barley to leaf rust, Puccinia hordei. V: Analysis of the components of partial resistance in eight barley cultivars. Euphytica, Wageningen, v. 27, p. 33-39, 1978.

OHM, H.W., SHANER, G.E. Three components of slow leafrusting at different growth stages in wheat. Phytopathology, St. Paul, v. 66, p. 1356-1360, 1976.

PARLEVLIET, J.E. Partial resistance of barley to leaf rust, Puccinia hordei. III: The inheritance of the host plant effect on latent period in four cultivars. Euphytica, Wageningen, v. 25, p. 241-248, 1976.

PARLEVLIET, J.E. Components of resistance that reduce the rate of epidemic development. Annual Review Phytopathology, Palo Alto, v. 17, p. 203-222, 1979

PARLEVLIET, J.E. What is durable resistance, a general outline. In: JACOBS, Th., PARLEVLIET, J.E. (eds.) Durability of disease resistance. Netherlands: Kluwer Academics, 1993. p. 23-39.

PARLEVLIET, J.E., VAN OMMEREN, A. Partial resistance of barley to leaf rust, Puccinia hordei. II: Relationship between field trials, micro plot tests and latent period. Euphytica, Wageningen, v. 24, p. 293-303, 1975.

PARLEVLIET, J.E., ZADOKS, J.C. The integrated concept of disease resistance, a new view including horizontal and vertical resistance in plants. Euphytica, Wageningen, v. 26, p. $5-21,1977$.

PARLEVLIET, J.E., VAN OMMEREN, A. Accumulation of partial resistance in barley to barley leaf rust and powdery mildew through recurrent selection against susceptibility. Euphytica, Wageningen, v. 37, p. 261-274, 1988.

PARLEVLIET, J.E., LINDHOUT, W.H., VAN OMMEREN, A., et al. Level of partial resistance to leaf rust, Puccinia hordei in west-european barley and how to select for it. Euphytica, Wageningen, v. 29, p. 1-8, 1980

PEARCE, W.L., VAN SANFORD, D.A. Partial resistance to powdery mildew in soft red winter wheat. Plant Disease, St. Paul, v. 80, p. 1359-1362, 1996.

PETERSON, R.F., CAMPBELL, A.B., HANNAH, A.E. A diagrammatic scale for estimating rust intensity of leaves and stem of cereals. Canadian Journal of Research Section, Ottawa, v. 26, p. 496-500, 1948.

ROUMEN, E. Response to selection for high and low partial resistance to leaf blast in $\mathrm{F} 2$ populations of three rice crosses. Euphytica, Wageningen, v. 89, p. 243-248, 1996.

SHANER, G., HESS, F.D. Equations for integrating components of slow leaf-rusting in wheat. Phytopathology, St. Paul, v. 68, p. $1464-1469,1978$

SHANER, G. Breeding for partial resistance in oat to rusts. In: V INTERNATIONAL OAT CONFERENCE \& VII INTERNATIONAL BARLEY GENETICS SYMPOSIUM, 1996. Saskatoon, Canada. Proceedings... Saskatoon: University of Saskatchewan, 1996. v. 1, 814 p., p. 307-313. 
SINGH, H., RAO, M.V. Area under the disease progress curve: Its reliability as a measure of slow-rusting resistance. Plant Breeding, Berlin, v. 103, p. 319-323, 1989.

SINGLETON, L.L., MOORE, M.B. WILCOXSON, R.D., et al. Evaluation of oat crown rust disease parameters and yield in moderately resistant cultivars. Phytopathology, St. Paul, v. 72, p. 568-540, 1982.

THOMÉ, G.C.H., MILACH, S.C.K., TEIXEIRA, M.C.C., et al. Image analysis for quantitative assessment of oat crown rust. Fitopatologia Brasileira, Brasília, v. 22, n. 4, p. 550-552, 1997a.

THOMÉ, G.C.H., MILACH, S.C.K., VOLK, L.B. da S.A., et al. Tamanho de pústula: um componente importante da resistência parcial à ferrugem da folha em aveia. Summa Phytopathologica, Jaboticabal, v. 23, p. 262-264, 1997b.
VAN DER PLANK, J.E. Plant diseases: epidemics and control. New York: Academic Press, 1963.

VAN GINKEL, M., RAJARAM, S. Breeding for durable resistance to diseases in wheat: an international perspective. In: JACOBS, Th., PARLEVLIET, J. E. (eds.) Durability of disease resistance. Netherlands: Kluwer Academics, 1993. p. 259-272.

WILCOXSON, R.D. Genetics of slow rusting in cereals. Phytopathology, St. Paul, v. 71, n. 9, p. 989-992, 1981.

YOUNG, N.D. QTL mapping and quantitative disease resistance in plants. Annual Review Phytopathology, Palo Alto, v. 34, p. $479-501,1996$

YU, Z.H., MACKILL, D.J., TANKSLEY, S.D. Tagging genes for blast resistance in rice via linkage to RFLP markers. Theoretical and Applied Genetics, Berlin, v. 81, p. 471-476, 1991.

Ciência Rural, v. 29, n. 2, 1999. 